\title{
A trajetória social da Irmã Tereza Araújo: serviço e contemplação ${ }^{1}$
}

\author{
Letícia Figueira Moutinho Kulaitis²
}

- Enviado em 26/02/2016

- Aprovado em 10/05/2016

\section{RESUMO}

Estudo da trajetória social da Irmã Tereza Araújo (1919-1981), religiosa da Congregação das Filhas da Caridade de São Vicente de Paulo que, na década de 1970 a 1980, realizou a primeira inserção religiosa em meio popular no bairro do Boqueirão e influenciou a atuação de obras comunitárias em Curitiba e Região Metropolitana de Curitiba, bem como do Centro de Formação Urbano-Rural Irmã Araújo, fundado em 1981.O objetivo central desta dissertação é reconstruir a trajetória social da Irmã Tereza Araújo, o que envolve investigar, sociologicamente, o modo como a religiosa percorreu o espaço social. Sendo assim, o problema de pesquisa levantado neste trabalho corresponde as seguintes questões: Como seu deu a trajetória social da Irmã Araújo?; Quais os aspectos da trajetória social da Irmã Araújo que fazem com que esta permaneça como influência nos trabalhos comunitários de Curitiba e Região Metropolitana?. Em Norbert Elias e Pierre Bourdieu foram encontradas as orientações teóricas e metodológicas necessárias à construção, em perspectiva sociológica, da biografia de um indivíduo. Portanto, conceitos como habitus, campo e trajetória social, em Bourdieu e configuração, interdependência e equilíbrio de poder, em Elias, assumem fundamental importância na realização deste trabalho. Além destes conceitos, o conceito de carisma é utilizado neste trabalho, como discutido por Bourdieu e Elias, para estabelecer a relação entre o histórico da Companhia das Filhas da Caridade e a trajetória da Irmã Tereza Araújo. Pode-se concluir que realizando de forma intensa o habitus vicentino, a Irmã Araújo destacou-se no campo religioso, pois sua dedicação aos princípios da Companhia das Filhas da Caridade valeu a religiosa um grande investimento da ordem em sua formação e o reconhecimento daqueles que conheceram seu trabalho.

Palavras-chave: Trajetória social. Habitus. Irmã Tereza Araújo.

\section{INTRODUÇÃO}

A dissertação, apresentada neste dossiê, tem como princípio o interesse científico despertado por monografia ${ }^{3}$, escrita em 2002, sobre a formação e a institucionalização do CEFURIA - Centro

\footnotetext{
${ }^{1}$ Dissertação defendida em 17 de setembro de 2004 no Programa de Pós-graduação em Sociologia da UFPR sob a orientação da Professora Doutora Maria Tarcisa Silva Bega. Versão completa disponível na Biblioteca Digital da UFPR - http://dspace.c3sl.ufpr.br/dspace/bitstream/handle/1884/1330.

${ }^{2}$ Graduada em Ciências Sociais pela Universidade Federal do Paraná. Mestre em Sociologia pela Universidade Federal do Paraná. Doutoranda do Programa de Pós-graduação em Sociologia da Universidade Federal do Paraná. Endereço eletrônico: leticia.kulaitis@gmail.com
} 
de Formação Urbano-rural Irmã Araújo, uma organização não-governamental de assessoria a movimentos sociais rurais e urbanos, com sede em Curitiba, Paraná.

Constatou-se, nessa pesquisa, que a primeira década de atuação do CEFURIA, de 1981 a 1991, foi marcada pela influência das obras comunitárias realizadas na periferia da cidade de Curitiba, em especial pela obra da Irmã Araújo, religiosa da Congregação das Filhas da Caridade de São Vicente de Paulo, no bairro do Boqueirão. Através desse primeiro levantamento, tornou-se evidente que o trabalho da religiosa serviu de modelo para o planejamento e realização das primeiras atividades do Centro de Formação.

Portanto, fez-se necessário no decorrer da pesquisa compreender a razão que levara os fundadores do Centro a denominá-lo de Centro de Formação Urbano-Rural Irmã Tereza Araújo. Era necessário, para tanto, descobrir quem foi a Irmã Araújo e reconstituir sua biografia. Buscando atingir este objetivo foram realizadas naquele período entrevistas com moradores do Boqueirão e Irmãs Vicentinas, congregação a que pertenceu a religiosa. Todos os entrevistados demonstraram satisfação em relatar os momentos de convivência com a religiosa e uma profunda admiração por seu trabalho.

Justamente por esta disposição encontrada entre os entrevistados, as informações levantadas, inicialmente, que iam além dos objetivos pretendidos para a realização de uma monografia sobre o CEFURIA, deram origem ao projeto de mestrado que baseou a dissertação, em questão, e cujo objetivo central era reconstruir a trajetória social da Irmã Tereza Araújo o que envolveu investigar, sociologicamente, o modo como a religiosa percorreu o espaço social.

O problema de pesquisa levantado, na dissertação, correspondeu ao seguinte conjunto de questões: Como se deu a trajetória social da Irmã Araújo?; Quais os aspectos da trajetória social da Irmã Araújo que lhe deram destaque no campo religioso? E por fim, quais os aspectos da trajetória social da Irmã Araújo que fazem com que esta permaneça como influência nos trabalhos comunitários de Curitiba e Região Metropolitana?

Tendo como referência a construção sociológica da biografia da Irmã, foram formuladas as seguintes hipóteses:

\footnotetext{
${ }^{3}$ MOUTINHO, Letícia Clément Figueira. Da inserção religiosa à assessoria popular: Trajetória da racionalização do CEFURIA. Curitiba, 2002, 57 p. Monografia (Bacharelado em Ciências Sociais) - Setor de Ciências Humanas, Letras e Artes, Universidade Federal do Paraná.
} 
a) A trajetória social da Irmã Araújo é marcada pela passagem por diversos campos sociais e pelo processo de atualização de seu habitus;

b) O carisma da Irmã Araújo associado a diferentes tipos de capitais são elementos que explicam seu destaque no campo religioso;

c) A fé, constitutiva do habitus religioso, aproximou a Irmã dos trabalhos comunitários, de orientação religiosa, realizados em Curitiba e Região Metropolitana.

O ponto de partida para a realização da dissertação foi um levantamento dos estudos sociológicos de trajetória social. Em Norbert Elias, Pierre Bourdieu e Sérgio Miceli, entre outros autores, foram encontradas as orientações teóricas e metodológicas necessárias à construção, em perspectiva sociológica, da biografia de um indivíduo. Assim conceitos como habitus, campo e trajetória social, em Bourdieu e configuração, interdependência e equilíbrio de poder, em Elias, assumiram fundamental importância na realização deste trabalho. Além destes conceitos, o conceito de carisma foi utilizado no trabalho, como discutido por Bourdieu e Elias, para estabelecer a relação entre o histórico da Companhia das Filhas da Caridade e a trajetória da Irmã Tereza Araújo.

Nesse sentido, a construção teórica do conceito de trajetória social, como proposta por Bourdieu, estabelece um contraponto entre esta pesquisa e as chamadas biografias institucionais, que têm por objetivo, através de alguns personagens, documentar a história de algumas instituições. De acordo com MICELI (1988, p. 54), no campo religioso:

\footnotetext{
O trabalho de resgate e conservação da memória organizacional [...] passando pelos livros de devoção, missais, manuais, breviários, novenas, pelos regulamentos, pelas obras monográficas a respeito de igrejas, santuários, conventos, ordens, irmandades, cultos e devoções populares, sociedades pias, seminários, escolas até os textos doutrinários, litúrgicos, e a imensa cópia de imagens com amplas tiragens (santinhos, oleografias, gravuras, etc), constitui um dos principais obstáculos sociais à apreensão de pesquisadores leigos que não estejam comprometidos com os interesses da hierarquia, e muito menos a seu serviço.
}

Em tais obras encontra-se o sentido da realização de uma hagiografia, ou seja, uma biografia excessivamente elogiosa de santos e religiosos. Sendo assim, o objetivo central destes trabalhos não é perceber tais indivíduos em suas relações sociais, mas os perceber como indivíduos cujas ações não estão relacionadas ao contexto social em que estão inseridos. Há, até mesmo, uma 
tentativa de desvincular o indivíduo de seu contexto social para que as ações individuais sejam vistas como geniais e ou pioneiras.

Verificando que um recurso metodológico indispensável para a reconstrução da trajetória social de um indivíduo é a reconstituição do ponto de vista do indivíduo, ou seja, a compreensão das escolhas feitas por este indivíduo no universo das escolhas a que ele se apresentaram, ou seja no chamado espaço dos possíveis BOURDIEU (2002, p. 17) foram realizadas diversas entrevistas que buscavam tal reconstituição.

Destaca-se também que dada a inexistência de uma biografia da Irmã Tereza Araújo, seja de caráter institucional ou autobiográfico, a construção do trabalho foi feita com dados primários recolhidos em entrevistas e pesquisas documentais.

\section{A TRAJETÓRIA SOCIAL COMO RELAÇÃO INDIVÍDUO E SOCIEDADE}

Um dos desafios propostos às Ciências Sociais, desde o seu surgimento, é a relação entre os conceitos de indivíduo e sociedade. É apresentada, nesta seção, a discussão feita por Norbert Elias e Pierre Bourdieu, acerca deste tema, por serem estas as orientações teóricas e metodológicas utilizadas para construir a trajetória social da Irmã Tereza Araújo, objeto de estudo da dissertação em questão, trazendo conceitos como campo, configuração, habitus, interdependência, entre outros, através dos quais é possível sistematizar, em perspectiva sociológica, a biografia de um indivíduo.

Elias defendia que os conceitos de indivíduo e sociedade devem ser discutidos em relação e não em oposição, como é feito usualmente, sem que sequer se observe o tratamento dado aos termos e os motivos deste tratamento. Sendo assim, o autor criticava o uso dos conceitos indivíduo e sociedade como dois termos completamente opostos.

Foram identificadas, por Elias, as seguintes acepções usuais dos termos indivíduo e sociedade. O primeiro é concebido como expressão da singularidade do ser humano. Já o segundo é percebido como a somatória dos indivíduos ou como algo que existe de forma independente dos indivíduos e que não pode ser explicado (ELIAS, 1994, p. 7). Não há portanto nenhuma relação estabelecida, a princípio, entre as definições usuais destes termos.

Contrapondo-se a estas concepções, Elias investigou o modo pelo qual os indivíduos ligamse entre si numa sociedade. O autor questionou "como é que eles (os indivíduos) formam uma 
'sociedade' e como sucede a essa sociedade poder modificar-se de maneiras específicas, ter uma história que segue um curso não-pretendido ou planejado por qualquer dos indivíduos que a compõem" (ELIAS, 1994, p. 16).

Elias acreditava que sua abordagem tornava o entendimento dos conceitos de indivíduo e sociedade mais concreto. E é neste contexto teórico que o autor desenvolveu o conceito de configuração, que se refere a "grupos interdependentes de pessoas, organizados em estados e não por indivíduos singulares interdependentes" (ELIAS, 1999, p. 31). A noção de interdependência, fundamental na definição do conceito de configuração, referia-se aos laços de dependência, sejam eles de propriedade, trabalho e afeto, que vinculam os indivíduos uns aos outros.

$\mathrm{Na}$ análise das configurações, os indivíduos singulares são apresentados da maneira como podem ser observados: como sistemas próprios, abertos, orientados para a reciprocidade, ligados por interdependências dos mais diversos tipos e que formam entre si figurações específicas, em virtude de suas interdependências (ELIAS, 2001, p. 51). Portanto, os indivíduos devem ser observados nas figurações específicas das quais fazem parte.

As configurações são permeadas por relações de poder, sempre em equilíbrio instável. Sendo assim, a individualidade e o comportamento de um indivíduo são incompreensíveis sem conhecimento do desenvolvimento de sua posição social no interior da estrutura de poder da sociedade na qual está inserido (ELIAS, 2001, p. 43). Assim os conceitos de indivíduo e sociedade são vistos como processos sociais que se diferenciam, mas que são indissociáveis.

Numa perspectiva próxima à de Elias, Pierre Bourdieu dedicou-se a seguinte problemática teórica: a mediação entre o agente social e a sociedade (ORTIZ, 1983, p. 8), utilizando como instrumentos metodológicos e teóricos, os conceitos de habitus e campo.

O conceito de campo é definido por Bourdieu, como um espaço estruturado de relações, onde as condições objetivas (aquelas que são da estrutura social) e as práticas sociais se manifestam. Pode ser definido ainda como uma esfera autônoma da vida social. A autonomia de cada campo apresenta-se nas relações sociais, conteúdos e recursos diferenciados que possuem, ou seja, como uma espécie de autonomia relativa.

A noção de campo, como apresentada por Bourdieu, é convergente, em Elias, ao conceito de configuração no que se refere ao "padrão mutável criado pelo conjunto de jogadores [indivíduos] não só pelos seus intelectos, mas pelo que eles são no seu todo, a totalidade das ações nas relações 
que sustentam uns com os outros" (ELIAS, 1999, p. 142). Assim, um campo ou uma configuração específica apresentam relações sociais também específicas.

Tanto Elias quanto Bourdieu observaram que em muitos estudos sociológicos fala-se do indivíduo como um elemento dissociado da sociedade, esquecendo que o indivíduo faz parte da sua sociedade. ELIAS (1999, p. 13) aponta que "a sociedade que é muitas vezes colocada em oposição ao indivíduo, é inteiramente formada por indivíduos, sendo nós próprios um ser entre os outros".

Por conta desta separação entre indivíduo e sociedade, grupos de seres humanos interdependentes como a família não são estudados como configurações específicas formadas pelos indivíduos. Numa concepção tradicional, a sociedade é formada por estruturas exteriores aos indivíduos e estes são, ao mesmo tempo, separados da sociedade e rodeados por ela.

Para Elias, dada a especificidade do campo de estudo da sociologia - as configurações de seres humanos interdependentes - torna-se fadada ao fracasso a realização de um estudo sociológico que investigue os indivíduos isoladamente. No entanto, o procedimento contrário é até mesmo aconselhável uma vez que "só podemos compreender muitos aspectos do comportamento ou das ações das pessoas individuais se começarmos pelo estudo do tipo da sua interdependência, da estrutura das suas sociedades, em resumo, das configurações que formam uns com os outros" (ELIAS, 1999, p. 79). Ou seja, analisando os tipos de relação estabelecidas no espaço social, ou mesmo, as regras em jogo nos campos sociais.

$\mathrm{O}$ autor utilizava a imagem dos participantes de jogo como uma metáfora das pessoas que formam as sociedades. Através do modelo de jogos é possível perceber "como a interdependência das pessoas enquanto jogadores exerce coacção sobre cada um dos indivíduos que estão ligados deste modo, a coacção radica na natureza particular da sua relação e dependência enquanto jogadores. Também nesta instância o poder, é a característica estrutural de uma relação" (ELIAS, 1999, p. 104). Deve-se pensar, segundo o autor, não no homem no singular mas sim numa multidão de pessoas, cada uma delas constituindo um processo aberto e interdependente.

Nas sociedades humanas, torna-se manifesta a profunda necessidade emocional que os seres humanos têm em relação uns aos outros. Esta questão e todas as outras questões colocadas por Elias são fundamentais se quisermos compreender quais as relações que ligam as pessoas umas às outras, constituindo os alicerces da sua interdependência. Para a compreensão do nexo de relações de uma pessoa isolada é necessário "voltarmos à teia de relações pessoais dessa pessoa isolada, para ver 
como é que ela aparece do seu ponto de vista - como é que é sentido do ponto de vista da perspectiva do 'eu'” (ELIAS, 1999, p. 150).

Dada a acepção de Elias dos conceitos de indivíduo e sociedade, é preciso considerar o indivíduo em suas relações com os outros indivíduos e não isoladamente. Construindo o modelo teórico das configurações, é possível verificar quais os limites que uma determinada configuração social impõe aos indivíduos e como os indivíduos se comportam diante destas limitações. Ou seja, de acordo com diferentes posições interdependentes, proporcionadas pelas configurações.

Numa abordagem semelhante à de Elias, de mostrar a relação entre os conceitos de indivíduo e sociedade, Bourdieu destaca os agentes em ação no campo ao construir o conceito de habitus.

O conceito de habitus é definido por BOURDIEU (1992, p. 191) como "sistema das disposições socialmente constituídas que, enquanto estruturas estruturadas e estruturantes, constituem o princípio gerador e unificador do conjunto das práticas e das ideologias características de um grupo de agentes". Sendo assim, pode ser entendido como um sistema de esquemas de pensamento interiorizados e socialmente constituídos, que é capaz de originar todos os pensamentos, percepções e as ações características de uma cultura.

De acordo com CORCUFF (2001, p. 33) Bourdieu e Elias "têm a particularidade de continuar a dar uma certa predominância às estruturas sociais e aos aspectos macrossociais da realidade, integrando de maneira variável, as dimensões subjetivas e interacionais".

O conceito de habitus, apresentado como um princípio gerador de práticas, indica ainda como Bourdieu percebeu a relação entre os conceitos de indivíduo e sociedade. É através da interiorização de normas, valores e princípios sociais que as ações dos indivíduos adequam-se à realidade objetiva da sociedade. Na formulação teórica apresentada por Bourdieu, os indivíduos realizam ações sociais concretamente, mas as possibilidades de realizá-las estão objetivamente estruturadas na sociedade. É nesse mesmo sentido, que Elias apontou as limitações que são colocadas aos indivíduos por uma determinada configuração.

Portanto, os estudos biográficos, de caráter sociológico, se contrapõem aos estudos biográficos literários que costumam apresentar o indivíduo e sua obra separadamente das relações em que estão inseridos, ou seja, sem relacioná-los às condições sociais de produção. De acordo com BOURDIEU (1992, p.183), "a história da literatura em sua forma tradicional [...] ignora quase 
completamente o esforço por reinserir a obra ou o autor singular que toma como objeto no sistema de relações constitutivo da classe dos fatos (reais ou possíveis) de que faz parte sócio-logicamente".

Seguindo esta perspectiva, um estudo biográfico, à luz da sociologia, deve "construir a hierarquia do sistema de fatores pertinentes quando se trata de dar conta de um campo ideológico que corresponde a um determinado estado da estrutura do campo intelectual" (BOURDIEU, 1992, p. 187). Grande parte dos estudos biográficos sociológicos dedicam-se às trajetórias sociais de literatos, intelectuais e artistas ${ }^{4}$. Propomos, no entanto, o estudo da trajetória social de uma religiosa com base na metodologia utilizada para o estudo de intelectuais e artistas, a chamada ciência das obras.

Bourdieu apontou as três operações que constituem a ciência das obras: a análise da posição do campo, em estudo, no seio do campo do poder, ao decorrer do tempo; a análise da estrutura interna deste campo, suas leis de funcionamento e de transformação; e por último, a análise dos habitus dos ocupantes dessas posições, ou seja, os sistemas de disposições, possíveis de atualização, que são o produto de uma trajetória social e de uma posição no interior do campo (BOURDIEU, 2002, p. 243).

Sem deixar de lado estas três operações, a categoria carisma como apresentada pelos autores Norbert Elias e Pierre Bourdieu permitiu associar as "qualidades individuais" da Irmã Araújo às relações e estruturas sociais, entendidas como "configurações" ou "campos", em que a religiosa estava inserida

De acordo com Elias, a tarefa do líder carismático era agrupar os indivíduos e reunir seus esforços em um mesmo sentido. Sendo assim, as aptidões extraordinárias, que são atribuídas ao líder carismático, só podem ser analisadas considerando a configuração específica que as proporcionaram.

Bourdieu revisou criticamente o conceito de carisma como proposto por Max Weber. Na concepção do autor, a força simbólica do profeta não está, como acredita Weber, em seu carisma pessoal mas sim no poder exercido pelos grupos sociais que representa. Tal perspectiva aproxima Bourdieu de Elias, pois ambos acreditam que para compreender a dominação exercida pelo profeta ou líder carismático é necessário compreender o campo social em que este se insere e suas relações de interdependência - para Elias - ou a posição relacional deste indivíduo no campo - para Bourdieu.

\footnotetext{
${ }^{4}$ Destacamos os estudos de Sérgio Miceli sobre os intelectuais brasileiros (MICELI, 2001) e de Maria Tarcisa Silva Bega sobre os poetas paranaenses representantes do simbolismo (BEGA, 2013).
} 
Desse modo, a concepção de carisma nos auxiliou na compreensão da posição ocupada pela Irmã Tereza Araújo no campo religioso desde a entrada na Companhia Filhas da Caridade de São Vicente de Paulo e na sua permanência como uma influência para os trabalhos comunitários realizados em Curitiba e Região Metropolitana até hoje.

\section{A COMPANHiA FILHAS DA CARIDAdE DE SÃO VICENTE DE PAULO E A FORMAÇÃO DE UM NOVO HABITUS}

Maria Pinheiro Araújo nasceu em Pacotí, no Estado do Ceará, em 26 de janeiro de 1919. Seu pai, José Monteiro Araújo, era agricultor e sua mãe, Maria Pinheiro Araújo, dona de casa.

Ainda no Ceará, Maria Pinheiro Araújo recebeu alguns dos principais sacramentos da Igreja Católica: foi batizada em 22 de fevereiro de 1920, fez sua primeira comunhão em 08 de dezembro de 1924 e crisma em 1927. O recebimento desses sacramentos afirma a religiosidade da família Araújo. Tal religiosidade pode ter ainda influenciado a entrada de Maria Araújo no campo religioso.

Aos 18 anos, Maria Pinheiro Araújo foi admitida na Companhia Filhas da Caridade de São Vicente de Paulo, da Ordem Vicentina, no Rio de Janeiro, sendo definida pela instituição como "vocacionada fervorosa" (SECRETARIA, 2000), embora o sentido de tal vocação não seja mencionado de forma clara nos escritos da Companhia. No dia 26 de agosto de 1939 recebeu o hábito da Companhia. Na festa de São Vicente de Paulo, em 19 de julho de 1943, fez os votos, passando a se chamar Irmã Tereza Araújo. A mudança de nome marca, mesmo que de forma simbólica, o rompimento com seu habitus original, proveniente de sua família, e a entrada no campo religioso.

Mas do que a mudança de nome, este rito de instituição marca como esclareceu Bourdieu "a instituição de uma identidade, que pode ser um título de nobreza ou estigma ('tu és um só'...), é a imposição de um nome, ou seja, de uma essência social. Instituir, conceder uma essência, uma competência é impor um direito de ser que é um dever ser (ou de ser). É significar a alguém aquilo que é e significar-lhe que deve conduzir-se de acordo com isso. O indicativo, neste caso, é um imperativo" (BOURDIEU, 1998, p. 113).

Sobre o significado de um rito de instituição como o vivido pela Irmã Araújo, Bourdieu argumentou que: 
Em resumo, sob pena de não conseguir compreender os fenômenos sociais mais fundamentais tanto nas sociedades pré-capitalistas como no nosso próprio mundo (o diploma pertence tanto à magia quanto os amuletos), a ciência social deve ter em conta o fato da eficácia simbólica dos ritos de instituição; quer dizer, o poder que estes detêm para agir sobre o real agindo sobre a representação do real. Por exemplo, a investidura exerce uma eficácia simbólica perfeitamente real ao transformar a representação que dela fazem os outros agentes e, sobretudo, os comportamentos que adotam em relação a ela (sendo a mudança mais visível sendo o fato de serem dados títulos de respeito e o respeito realmente associado a esta enunciação); e, depois, porque transforma simultaneamente a representação que a pessoa investida faz de si própria e os comportamentos que julga dever adotar para se conformar com esta representação. Podemos compreender nesta lógica o efeito de todos os títulos sociais de crédito ou de crença - os Ingleses chamam-lhe credencials - que, como o título de nobreza ou o título escolar, multiplicam de forma durável, o valor do seu portador, ao multiplicar o alcance e a intensidade da crença no seu valor (BOURDIEU, 1998, p. 112).

Embora não tenha sido possível levantar, no decorrer do trabalho de pesquisa, as circunstâncias que levaram a entrada da Irmã Araújo no campo religioso, MICELI (2001, p. 23) ressaltou que a "escolha" de uma profissão ou até mesmo de uma "vocação" pode estar relacionada a estratégias de reconversão de capital. Desse modo, o autor afirmou que:

Para aquelas famílias em declínio que ocupam uma posição em falso em virtude do desequilíbrio entre o capital material dilapidado e o capital social disponível, a única possibilidade de reconversão depende das possibilidades de fazer valer o capital de relações sociais - em especial em conjunturas estratégicas como a educação dos filhos, a 'escolha' dos cursos superiores, o casamento, a nomeação para cargos públicos etc.-, por ser o único com que ainda podem contar para escapar a um rebaixamento social ainda maior (MICELI, 2001, p.23).

No entanto, Miceli apontou que, em geral, estas estratégias de reconversão de capital não conseguiam devolver a essas famílias sua posição social anterior. Dado que "para as famílias em apreço, a prestação de serviços à Igreja se insere num cálculo complexo de sobrevivência social, dando origem a uma espécie de capital dificilmente conversível, em outros setores da classe dominante" (MICELI, 1988, p. 93). Assim como a "escolha" da profissão, a inserção na Igreja pode ser concebida como um cálculo complexo de sobrevivência social o que afirma a importância da origem social na entrada do campo religioso.

Miceli indicou ainda que as estratégias de reconversão de capital estão associadas ao estado do campo. Sendo assim "se as famílias de 'parentes pobres' tiveram êxito em fazer valer seu capital social, isso se deve ao fato de que suas estratégias de reconversão coincidiram com um momento determinado de expansão do mercado de postos disponíveis, que veio favorecer seus interesses" 
(MICELI, 2001, p.23). No caso da religiosa, a possibilidade de deixar o campo e buscar formação escolar em nível superior e a devoção religiosa de sua família são elementos que podem ter favorecido a "escolha" do trabalho religioso.

No entanto, sejam quais forem as circunstâncias que marcaram a entrada de um indivíduo num determinado campo, como o campo religioso, Bourdieu salientou que a vinculação ao campo “implica a aceitação de um conjunto de pressupostos e postulados que, sendo a condição indiscutida das discussões são, por definição, mantidos a salvo das discussões” (BOURDIEU, 2002, p. 193).

Como um sistema simbólico estruturado, a religião, especificamente, assume uma função ideológica, de legitimação de um determinado estilo de vida. A religião "inculca um sistema de práticas e representações consagradas cuja estrutura (estruturada) reproduz sob uma forma transfigurada, e portanto irreconhecível, a estrutura das relações econômicas e sociais vigentes em uma determinada formação social" (BOURDIEU, 2001, p. 46).

Faz-se necessário, portanto, a formação, no indivíduo, de um novo habitus o que, por sua vez, implica em inculcar esquemas de pensamento, ação e percepção próprios deste campo.

\section{O HABITUS COMO UMA SEGUNDA NATUREZA: A TRAJETÓRIA SOCIAL DA IRMÃ TEREZA ARAÚJO}

Esta pesquisa teve como principal orientação teórica e metodológica a chamada "Ciência das obras" tal como formulada por Bourdieu. Realizando uma análise sociológica da trajetória de um indivíduo e de suas relações com diferentes campos sociais, o autor desenvolveu e aplicou um modelo de investigação que revisa conceitos clássicos das Ciências Sociais como indivíduo e sociedade.

Desse modo, ao recusar a dicotomia indivíduo e sociedade "Bourdieu passa a insistir na necessidade de buscar no campo [conceito por ele elaborado] as condições sociais de operação do sujeito e de sua atividade de elaboração do objeto, cravando lentes tanto nas conquistas como nos limites de seus atos e práticas de objetivação" (MICELI, 2003, p. 73).

Tal formulação teórica e metodológica comumente utilizada no exame da trajetória social de intelectuais, artistas e escritores é aplicada, nesta dissertação, na análise da trajetória de uma religiosa tornando possível a compreensão do modo como a Irmã Araújo percorreu o espaço social. 
Foram analisadas as posições ocupadas sucessivamente pela religiosa no espaço social desde o ponto de partida de sua trajetória no município cearense de Pacotí até o fim de sua vida em Curitiba. Esse processo é atravessado pela realização de um habitus, ou seja, na constituição de práticas e ideologias que "poderão atualizar-se em ocasiões mais ou menos favoráveis que lhe propiciam uma posição e uma trajetória determinadas no interior do campo [...] que, por sua vez, ocupa uma posição determinada na estrutura da classe dominante" (BOURDIEU, 1992, p. 91). Ao exteriorizar a formação de um habitus interiorizado, a Irmã Araújo realiza uma determinada trajetória no campo religioso e no espaço social, de forma mais geral.

Ao entrar na Companhia das Filhas da Caridade de São Vicente de Paulo, no Rio de Janeiro, e receber o hábito de religiosa em 1939, a Irmã Araújo passou por um processo de inculcação de esquemas de pensamento, ação e percepção que mais tarde seriam exteriorizados em sua prática.

Nesse sentido, Miceli afirma que:

Dessa perspectiva [o conceito de habitus como apresentado por Bourdieu], a prática emergia como algo justificado em decorrência do seu contexto, e ao mesmo tempo, como uma conduta dotada de certa autonomia em relação à situação de ocorrência, ou melhor, como produto de uma relação dialética entre um contexto e um habitus, uma conduta resultante de uma matriz de percepções, apreciações e outras ações que se esgueiram em meio às construções sem se deixar determinar completamente pelas mesmas (MICELI, 2003, p. 70-71).

Formada em Enfermagem, a Irmã Araújo correspondeu à orientação da Companha Filhas da Caridade de São Vicente de Paulo de atuação na área da saúde e educação. Este é um dos aspectos do carisma vicentino que são associados individualmente à Irmã Tereza Araújo.

A religiosa seguiu do Rio de Janeiro para Presidente Prudente, em São Paulo, onde em 1939 trabalhou na Santa Casa. De volta ao Rio de Janeiro, onde fez os votos em 1943, atuou como professora de Obstetrícia e Ginecologia na Pontifícia Universidade Católica do Rio de Janeiro. Entre 1946 e 1947 trabalhou na Santa Casa e no Hospital Pedro II, no Estado do Rio de Janeiro.

Em Recife, a Irmã fundou a Faculdade de Enfermagem do Recife. Em sua passagem pelo Nordeste esteve também na província de Teresina, no Piauí.

Irmã Araújo chegou ao estado do Paraná em 1956, onde fundou, na cidade de Apucarana, um novo hospital. Trabalhou, em seguida, como superiora e diretora deste hospital até 1964 quando assumiu o cargo de superiora no Hospital de Clínicas de Curitiba, onde acompanhou os estudantes de medicina, residentes no hospital. 
Retornando à sua província de origem, o Rio de Janeiro, ao cursar o Instituto de Pastoral Catequética - ISPAC, no ano de 1969, a Irmã Araújo aproximou-se de uma nova forma de atuação, desenvolvida pela Conferência Nacional dos Bispos do Brasil, o trabalho em pastorais ou nas chamadas comunidades eclesiais de base e é ainda através deste trabalho, mais especificamente da Pastoral Carcerária, que realiza uma nova posição no campo religioso: a participação política.

Em sua passagem pela cidade do Rio de Janeiro, a Irmã Araújo vivenciou as mudanças provocadas pela instauração do regime de ditadura militar no Brasil em 31 de março de 1964. A proximidade com religiosos perseguidos pelo regime fez com que a Irmã retornasse a Curitiba disposta a se dedicar ao trabalho junto aos presos políticos na Pastoral Carcerária.

O trabalho na Pastoral Carcerária marca de forma clara, na trajetória da Irmã Araújo, a necessidade de atualizar seu habitus religioso. Quando abrigou estudantes presas sob regime domiciliar na Casa Provincial de Curitiba, a Irmã Araújo rompeu seu voto de obediência busca uma nova orientação - o disfarce de pensionistas - para a resolução da situação.

Neste mesmo período, apesar de dedicada ao trabalho de formação de catequistas, a Irmã manifestava sua preocupação em realizar uma ação junto à população de baixa renda em Curitiba. Tal preocupação está relacionada à formação de seu habitus religioso que inculcou a necessidade de serviço e dedicação aos pobres.

Dado que "o habitus é esse princípio gerador e unificador que retraduz as características intrínsecas e relacionais de uma posição em um estilo de vida unívoco, isto é, em um conjunto unívoco de escolhas de pessoas, de bens, de práticas" (BOURDIEU, 1996, p. 22). A escolha da Irmã Araújo é a realização da exteriorização de um habitus interiorizado, vivido por ela como uma segunda natureza.

Ainda de acordo com Bourdieu, "a estratégia universalmente adotada para recusar de maneira duradoura a tentação de derrogar consiste em naturalizar a diferença, a fazer dela uma segunda natureza por meio da inculcação e da incorporação sob a forma de habitus" (BOURDIEU, 1998, p. 116).

As percepções e atitudes dos indivíduos são condicionadas pela posição que ocupam no espaço social e seu habitus entendido como um sistema que ao mesmo tempo produz determinadas práticas e também percebe e aprecia as práticas, em operações que exprimem a posição do agente.

Ao lado das Irmãs Maria Lídia Pancera, Lidinha e Adiles Zangrande, a Irmã Araújo passou a residir no bairro do Boqueirão no ano de 1973. Num período de aproximadamente oito anos (1973 
- 1981), as religiosas e os moradores formaram uma associação comunitária, uma fábrica de artefatos de cimento, um posto de saúde e lutaram para dotar o bairro de infra-estrutura urbana. Além disso, foi formado no bairro um grupo de catequistas responsável pela orientação religiosa da comunidade.

Ao se tornar religiosa, a Irmã Araújo passou a ser portadora de um carisma de função e é no bairro do Boqueirão que a Irmã Araújo foi reconhecida como uma líder carismática, responsável pelas transformações ocorridas neste espaço e pelas conquistas da associação comunitária.

Através da transmissão do carisma, rotinizado por meio de uma instituição como a Igreja Católica, o carisma deixa de ser um atributo pessoal tornando-se um atributo do ofício. No entanto, a realização do carisma vicentino foi tomada com uma característica individual da religiosa que parece apresentar uma resposta imediata a cada situação de crise enfrentada pela comunidade.

Bourdieu afirmou que o carisma de função é uma espécie de ideologia profissional representa e designa "as propriedades simbólicas (em primeiro lugar, a eficácia simbólica) que se agregam aos agentes religiosos na medida que aderem à ideologia do carisma, isto é, o poder simbólico que lhes confere o fato de acreditarem em seu próprio poder simbólico" (BOURDIEU, 2001, p. 55).

Ao realizar a inserção em meio popular no bairro do Boqueirão, ação pioneira no campo religioso, a Irmã Araújo orientou o trabalho junto aos moradores de acordo com a formação de seu habitus religioso. Sendo assim, a religião teve um papel fundamental na inserção aproximando os moradores e as religiosas. Através da religião, os moradores, que no campo religioso ocupavam a posição de leigos, puderam ajustar seus esquemas de percepção e apreciação de acordo com a orientação do habitus das religiosas vicentinas.

Sobre a relação entre leigos e religiosos, Bourdieu esclareceu que:

Em função de sua posição na estrutura da distribuição do capital de autoridade propriamente religiosa, as diferentes instâncias religiosas, indivíduos ou instituições, podem lançar mão do capital religioso na concorrência pelo monopólio da gestão dos bens de salvação e do exercício legítimo do poder religioso enquanto poder de modificar em bases duradouras as representações e as práticas dos leigos, inculcando-lhes um habitus religioso, princípio gerador de todos os pensamentos, percepções e ações, segundo as normas de uma representação religiosa do mundo natural e sobrenatural, ou seja, objetivamente ajustados aos princípios de uma visão política do mundo social” (BOURDIEU, 2001, p. 57).

A criação do Posto de Saúde Comunitário foi a última realização da Irmã Araújo, que faleceu em março de 1981. No entanto, após seu falecimento, a religiosa considerada responsável 
por um trabalho comunitário bem-sucedido passou receber homenagens e nomear trabalhos com propósitos semelhantes: o Posto de Médico Comunitário Irmã Araújo, o Centro de Formação Urbano-Rural Irmã Araújo e a Casa Irmã Araújo em Almirante Tamandaré. Ao entrar no campo religioso e exteriorizar de forma intensa o habitus vicentino por ela interiorizado, a Irmã Araújo realizou uma trajetória social capaz de influenciar a sua geração e gerações posteriores.

\section{CONSIDERAÇÕES FINAIS}

Atendendo os princípios da Companhia das Filhas da Caridade, a Irmã Araújo procurou realizar de diferentes maneiras sua missão de dedicação aos pobres, seja trabalhando na Pastoral Carcerária, com presos comuns e políticos, seja realizando a primeira inserção em meio popular no bairro do Boqueirão ou dedicando-se a enfermagem.

A dedicação aos princípios da Companhia valeu a Irmã Araújo um grande investimento da Ordem em sua formação profissional. Tal afirmação comprova-se pelos cursos realizados pela religiosa, como o ISPAC - Curso Superior de Pastoral e por sua passagem pelas diferentes províncias que compõem a Companhia das Filhas da Caridade, como Rio de Janeiro, Recife, Piauí e São Paulo

Realizando de forma intensa o habitus vicentino, a Irmã Araújo destacou-se no campo religioso e seu trabalho no bairro do Boqueirão tornou-se um modelo para a realização de trabalhos comunitários em Curitiba e Região Metropolitana como o trabalho realizado pelo CEFURIA e pela Casa Irmã Araújo, mantida pela Associação Luísa de Marillac em Almirante Tamandaré.

Em homenagem, nas comemorações dos 20 anos do CEFURIA, em 04 de agosto de 2001, foi lançado o Prêmio Irmã Araújo a entidades que foram destaques na luta por justiça. A primeira vencedora do prêmio foi a Irmã Adiles Zangrande, destaque por seu trabalho no bairro do Sítio Cercado, em Curitiba.

Após a realização deste trabalho, a expectativa é de que o estudo da trajetória social da Irmã Tereza Araújo possa contribuir para a compreensão da relação entre os conceitos clássicos das Ciências Sociais de indivíduo e sociedade e dos fatores que propiciam a realização de uma biografia com capacidade de influenciar gerações posteriores. 
Espera-se ainda que as lacunas deixadas pelo trabalho no que diz respeito a dados e fatos da biografia da religiosa, limites encontrados na realização da dissertação, não impeçam a compreensão de seus objetivos.

\section{REFERÊNCIAS}

BEGA, Maria Tarcisa Silva. Letras e Política no Paraná: Simbolistas e Anticlericais na República Velha. Curitiba: Editora UFPR, 2013.

BOURDIEU, Pierre. Campo do Poder, Campo Intelectual e Habitus de Classe. In: A economia das trocas simbólicas. São Paulo: Perspectiva, 1992. p. 183-202.

. Razões práticas. Sobre a teoria da ação. São Paulo: Papirus, 1996

. O que falar quer dizer. Miraflores: Difel, 1998.

BOURDIEU, Pierre. Gênese e estrutura do campo religioso. In: A economia das trocas simbólicas. São Paulo: Editora Perspectiva, 2001. p. 27-98.

As regras da arte. São Paulo: Companhia das Letras, 2002.

CORCUFF, Phillipe. As Novas Sociologias. Construções da realidade social. São Paulo: EDUSC, 2001.

ELIAS, Norbert. A sociedade dos indivíduos. Rio de Janeiro: Zahar, 1994.

. Introdução à Sociologia. Lisboa: Edições 70, 1999.

Introdução: sociologia e história. In: ELIAS, Norbert. A sociedade de corte. Rio de Janeiro: Zahar, 2001. p. 27-59.

MICELI, Sérgio. A elite eclesiástica brasileira. Rio de Janeiro: Bertrand Brasil, 1988.

. Elementos para leitura do quadro. In: MICELI, Sérgio. Intelectuais à brasileira. São Paulo: Cia. das Letras, 2001. p.22-26 
Bourdieu e a renovação da sociologia contemporânea da cultura. In: Revista Tempo

Social, USP, Abril/2003. p. 63-79.

ORTIZ, Renato. Introdução. A procura de uma sociologia da prática. In: BOURDIEU, Pierre.

Pierre Bourdieu. Coleção Grandes Cientistas Sociais. São Paulo: Ática, 1983. p. 7 - 36.

SECRETARIA da Província das Filhas da Caridade. Plenária Irmã Araújo. Irmã Araújo passou por esta terra fazendo o bem. p. 56-57. Curitiba: 2000. Não publicado.

\title{
The social trajectory of Sister Teresa Araujo: service and contemplation
}

\begin{abstract}
Study of the social history of Sister Tereza Araújo (1919-1981), religious of the Congregation of the Daughters of Charity of Saint Vincent de Paul who, in the decade from 1970 to 1980, held the first religious insertion into popular medium in the neighborhood of Boqueirão and influenced performance of community works in Curitiba and Metropolitan Region of Curitiba, as well as the Centro de Formação Urbano-Rural Irmã Araújo, founded in 1981. The central objective of this work is to rebuild the social trajectory of Sister Teresa Araujo, which involves investigating sociologically how that religious toured the social space. Thus, the research problem raised in this study correspond to the following questions: How gave his social trajectory of Sister Araújo ?; What aspects of the trajectory social Sister Araújo that make this stay as an influence in the community work of Curitiba and metropolitan region ?. Norbert Elias and Pierre Bourdieu found the theoretical and methodological guidelines needed to build, in sociological perspective, the biography of an individual. Therefore, concepts such as habitus, field and social trajectory, in Bourdieu and configuration, interdependence and balance of power in Elias, are of fundamental importance in this work. In addition to these concepts, charisma concept is used in this work, as discussed by Bourdieu and Elias, to establish the relationship between the Company's history of the Daughters of Charity and the trajectory of Sister Teresa Araujo. It can be concluded that performing intense Vincentian habitus, Sister Araújo said in the religious field, for his dedication to the principles of Charity of the Daughters Company paid religious a great investment of the order in their training and the recognition of those who They knew his work.
\end{abstract}

Keywords: Social history. Habitus. Sister Tereza Araújo 